\title{
Effect of pre-treatments and drying methods on nutrient composition and sensory quality of milk yam (Ipomoea digitata L.) tuber powder
}

\author{
- N. S. Sonia*, P. C. Jessykutty and G. S. SReEkala \\ Department of Plantation Crops and Spices, College of Agriculture (K. A.U.), VELLAYANI (KERALA) INDIA \\ Email : coa2008soniya@gmail.com; pcjessy@gmail.com;drsreekalags@gmail.com
}

*Author for Correspondence $\quad$ Research chronicle : Received : 05.07.2017; Revised : 03.11.2017; Accepted : 17.11.2017

\begin{abstract}
SUMMARY :
Milk yam (Ipomoea digitata L.) (Family-Covolvulaceae) or Ksheervidari is a potential medicinal cum nutraceutical agent. It is a perennial climber having tuberous roots which are medicinal. Dried and powdered tubers are used in several nutraceutical preparations. The present study focussed on different pre-treatments and drying techniques that can be adopted for improving the flour whiteness and quality of milk yam tuber powder. Peeled as well as non-peeled tubers were shredded and washed (three times, two times, single time and no washing), de-watered by keeping in bamboo basket. These tuber shreds were dried under sun and in a hot-air oven $\left(60^{\circ} \mathrm{C}, 70^{\circ} \mathrm{C}\right.$ and $\left.80^{\circ} \mathrm{C}\right)$. The samples were evaluated for micronutrients, non-nutrient but beneficial components as well as sensory quality attributes.Milk yam tuber powder prepared by three times washed peeled tuber shreds dewatered by keeping in bamboo basket and dried in hot-air oven at $60^{\circ} \mathrm{C}$ recorded optimum micronutrients, non-nutrient but beneficial components and sensory (overall visual quality - OVQ) quality attributes. Micronutrients composition include, calcium- $3.40 \mathrm{mg} / 100 \mathrm{~g}$, iron- $2.47 \mathrm{mg} / 100 \mathrm{~g}$, sodium- $2.53 \mathrm{mg} / 100 \mathrm{~g}$, high vitamin A $(613.33 \mu \mathrm{g} / 100 \mathrm{~g})$ and vitamin C (7.43 mg/100g). Non-nutritional but beneficial components viz., crude fibre-7.13 g/100g and total ash-3.56 g/100g. Mean rank value for the overall visual quality (OVQ) is 288.55 .
\end{abstract}

KEY WORDS : Beneficial components, Ksheervidari, Micronutrients, Nutraceutical, Overall visual quality

How to cite this paper : Sonia, N.S., Jessykutty, P.C. and Sreekala, G.S. (2017). Effect of pre-treatments and drying methods on nutrient composition and sensory quality of milk yam (Ipomoea digitata $\mathrm{L}$.) tuber powder. Internat. J. Proc. \& Post Harvest Technol., 8 (2) : 75-82. DOI: 10.15740/HAS/IJPPHT/8.2/75-82. 